\title{
Pattern of beverage consumption and long-term association with body-weight status in German adolescents - results from the DONALD study
}

\author{
Lars Libuda $^{1}$, Ute Alexy ${ }^{1}$, Wolfgang Sichert-Hellert ${ }^{1}$, Peter Stehle ${ }^{2}$, Nadina Karaolis-Danckert ${ }^{1}$, \\ Anette E. Buyken ${ }^{1}$ and Mathilde Kersting ${ }^{1}$ \\ ${ }^{1}$ Research Institute of Child Nutrition (FKE), Heinstueck 11, D-44225 Dortmund, Germany \\ ${ }^{2}$ IEL - Nutritional Physiology, Rheinische Friedrich-Wilhelms-Universität Bonn, Germany \\ (Received 19 January 2007 - Revised 25 September 2007 - Accepted 28 September 2007 - First published online 7 January 2008)
}

In the present study the relationship between the consumption of different beverage groups and body-weight status in 5 years of study participation in German adolescents was investigated. We used anthropometric and dietary data from $3 \mathrm{~d}$ weighed records of 244 subjects between 9 and 18 years of age participating in the Dortmund Nutritional and Anthropometric Longitudinally Designed (DONALD) study. Only subjects with at least four out of six possible weighed dietary records were considered. A repeated-measures regression model (PROC MIXED) was used to analyse the effect of beverage consumption on body-weight status. BMI standard deviation scores (BMI-SDS) and body fat percentage (\%BF) were chosen as the dependent variables. In boys, energetic beverage consumption was not associated with BMI-SDS or \%BF, neither cross-sectionally nor prospectively. In girls, baseline consumption of energetic beverages did not predict baseline BMI-SDS, baseline \%BF, or change in either variable over the study period. However, an increase in energetic beverage consumption over the study period was associated with an increase in BMI-SDS (+0.070 SDS/MJ increase in energetic beverage consumption; $P=0.01)$. Separate consideration of regular soft drinks and fruit juices revealed that, in girls, BMI-SDS increased with increased fruit juice consumption (+0.096 SDS/MJ increase in fruit juice consumption; $P=0.01)$, and to a lesser extent with regular soft drink consumption $(+0.055$ SDS/MJ increase in regular soft drink consumption; $P=0.08)$. In conclusion, these results suggest that an increase in energetic beverage consumption may result in weight gain, at least in adolescent girls.

Energetic beverages: Soft drinks: Drinking patterns: Body-weight status: Adolescents

Obesity in childhood and adolescence has become an increasingly serious issue worldwide ${ }^{(1,2)}$. In Germany $15 \%$ of children and adolescents between the ages of 3 and 17 years are overweight, and more than $6 \%$ are classified as obese ${ }^{(3)}$. Since the treatment of obesity has turned out to be difficult and inefficient for achieving sustainable long-term results, the prevention of overweight and obesity in childhood is of major public health interest ${ }^{(4)}$.

Data from the USA show that the proportion of energy obtained from sugar-sweetened soft drinks and fruit drinks increased 3-fold between 1977 and $1996^{(5)}$, and sugar-sweetened drinks constitute the primary source of added sugars in the American diet ${ }^{(6,7)}$. Malik et al. ${ }^{(8)}$ concluded in their recent review that greater consumption of sugar-sweetened drinks is associated with weight gain and obesity. There are suggestions of an incomplete compensation for energy consumed in liquid form ${ }^{(9-11)}$. With this in mind, fruit juices as a source of sugar are also under discussion ${ }^{(12)}$.

Dietary habits and food product composition are countryspecific. In Germany, beverage consumption patterns in adolescents might be different from the USA, where most studies on the effects of soft drinks on body weight were conducted. Additionally, German soft drinks and those from other
European countries are commonly sweetened with sucrose and not with high-fructose maize syrup as is the case in the $\mathrm{USA}^{(13)}$. Since high-fructose maize syrup in soft drinks is supposed to be one factor that may act adipogenicly, the results of US studies might not be transferable to other countries.

Therefore, in a first step, we examined the 5-year consumption patterns of soft drinks (regular and diet) and fruit juices, and the changes in consumption during the observation period in a group of German adolescents from the Dortmund Nutritional and Longitudinally Designed (DONALD) study. In a second step, we focused on the association between the consumption of these beverages and body-weight status.

\section{Study design and methods}

Study design

The DONALD study is an ongoing longitudinal (open cohort) study established in 1985 at the Research Institute of Child Nutrition in Dortmund. The DONALD study collects information on the nutrition, development, metabolism and health status of subjects between infancy and early adulthood. The regular assessments begin at 3 months of age, take place 
annually from the age of 2 years onwards, and include $3 \mathrm{~d}$ weighed dietary records, anthropometry, urine sampling, as well as interviews on lifestyle and medical assessments. About forty to fifty subjects are enrolled in the DONALD study each year. Further details of the DONALD study are provided elsewhere ${ }^{(14)}$.

The DONALD study is exclusively observational, non-invasive and approved by the ethical committee of the Rheinische Friedrich-Wilhelms-Universität Bonn (Germany). All examinations and assessments are performed with parental, and later on with the children's written consent.

\section{Study sample}

A previous analysis of DONALD data suggested the highest average soft drink consumption in children after the age of 9 years $^{(15)}$. To date, 1170 subjects have been enrolled in the DONALD study since 1985 . The ages of the children who were initially recruited into the DONALD study were quite variable. In addition, many children have not yet reached 14 years of age. Of the 1170 subjects 309 were $14-18$ years of age at the time of their last assessment. Of those, 277 had completed at least four out of six possible dietary records during the 5-year period, i.e. our sample covers the age range of 9-18 years. From these, thirty-three potential under-reporters were excluded, i.e. we only considered dietary records with a ratio of reported total energy intake and predicted individual $\mathrm{BMR}^{(16)}$ above the age- and sex-specific cut-off values of 1.04 for boys and 1.01 for girls (6-13year-old subjects) and of 1.07 for boys and 0.97 for girls (14-18-year-old subjects) $^{(17)}$

Our selection resulted in 1316 dietary records from 244 subjects (5.8 records per subject); 125 boys and 119 girls.

\section{Dietary survey}

All foods and beverages before consumption as well as leftovers were weighed and recorded by the parents of the children, or by the older subjects themselves, on three consecutive days ( $3 \mathrm{~d}$ weighed dietary records). The participants chose the first day of dietary recording within a given period of time. Regarding all recording days in the study sample, weekdays $(75.6 \%)$ and weekend days $(24.4 \%)$ were proportionally distributed. Semi-quantitative recording (for example, numbers of glasses, cups) was allowed, if weighing was not possible.

Energy and nutrient intakes were calculated using our inhouse nutrient database LEBTAB, which contains detailed data on the energy and nutrients content of all recorded food items and is continuously updated ${ }^{(18)}$. The nutrient content of basic food items was taken from standard nutrient tables; the content of commercial food items was derived either from the product labels or from simulating recipes from the ingredients listed on the labels.

For this analysis, beverage groups were defined as:

(1) Regular soft drinks: carbonated and uncarbonated sugarsweetened drinks such as lemonades, iced tea and fruit drinks (diluted and sugar-sweetened fruit juices), sports drinks and energy drinks;

(2) Diet (low-energy) soft drinks;
(3) Fruit juices (100\% juice);

(4) Energetic beverages: a combined variable made up of both regular soft drinks and fruit juices.

\section{Anthropometric measurement}

Anthropometric measurements were made at the time of the dietary records. Body weight was measured to the nearest $0 \cdot 1 \mathrm{~kg}$ using an electronic scale (Seca $753 \mathrm{E}$ ). Height was measured in a standing position to the nearest $0.1 \mathrm{~cm}$ using a digital telescopic stadiometer (Harpenden). BMI was calculated as body weight $(\mathrm{kg})$ divided by height $(\mathrm{m})$ squared. Sex- and age-independent BMI standard deviation scores (BMI-SDS) were calculated using the German national reference data ${ }^{(19)}$. Overweight was defined as BMI values between the 90th and the 97th percentile, obesity as BMI values above the 97th percentile of German national reference data.

Triceps and subscapular skinfolds were measured on the right side of the body using a skinfold calliper (Holtain Ltd, Crosswell, Dyfed, UK). The sum of both skinfolds was used for the estimation of body fat percentage (\%BF) according to the equations of Slaughter ${ }^{(20)}$. BMI-SDS and $\% \mathrm{BF}$ were used as parameters of body-weight status.

Information on weight at birth was abstracted from the 'Mutterpass', a standardised document given to all pregnant women in Germany, where anthropometric data at birth are obligatorily recorded. Parents were weighed and measured by the study nurses after their child's admission to the DONALD study; based on this information maternal BMI was calculated.

\section{Statistical analysis}

SAS ${ }^{\circledR}$ procedures (version 8.02, 2001; SAS Institute, Cary, NC, USA) were used for data analysis.

Intakes of energy and beverage groups were calculated as individual means of the $3 \mathrm{~d}$ weighed records. For comparison with the consumption of adolescents in the USA, long-term consumption, given as $\mathrm{g} / \mathrm{d}$, was calculated as the individual mean of the intakes recorded in the 5-year study period. The Wilcoxon rank sum test was used for testing differences between sexes. Differences in frequencies of overweight and obesity were analysed using the Fisher's exact test. Differences between baseline (first individual assessment) and last individual assessment values were tested by the Wilcoxon signed-rank test.

For analysing the association between beverage consumption and body-weight status the energy derived from a particular beverage group (MJ) was chosen as an indicator of beverage consumption. In contrast to the amounts in grams the latter variable further considers the differences in energy density within a particular beverage group. Due to the small number of subjects who consumed diet soft drinks in the study period (thirty-three boys and forty-five girls), diet soft drinks were excluded from the analysis of the association between beverage consumption and body-weight status. In the repeated-measures regression models regular soft drinks and juices were included at the same time as independent variables to consider possible mutual confounding. A repeatedmeasures regression model (PROC MIXED) was used for testing the association between baseline beverage consumption (MJ) and baseline values of body-weight status, baseline beverage 
consumption and change in body-weight status over a 5-year period, and change in beverage consumption and concurrent change in body-weight status. Separate analyses included either BMI-SDS or \% BF as the dependent variables. Due to a significant interaction with sex, we analysed boys and girls separately. An exponential variance structure was assumed. This supposes a stronger correlation of assessments of one subject in 2 consecutive years than for a longer time interval.

For BMI-SDS, the basic model included time in years ( 0 for the first assessment), age, baseline consumption of each beverage group (MJ), the interaction between baseline consumption with time, and the change in consumption in the 5-year study period (MJ). The change in beverage consumption (MJ) was calculated by subtracting baseline consumption from the consumption at each year of assessment (MJ). In this way, the regression coefficient of baseline beverage consumption represents the slope of the dependent variable (i.e. BMI-SDS or $\% \mathrm{BF})$ at the first assessment on consumption at the first assessment. The regression coefficient of the interaction between baseline beverage consumption with time represents the slope of the change in the dependent variable (i.e. BMISDS or \%BF) on beverage consumption at the first assessment. The regression coefficient of the change in beverage consumption represents the slope of the change in the dependent variable (i.e. BMI-SDS or \%BF) on the concurrent change in beverage consumption (last assessment minus first assessment).

Due to the linear development of $\% \mathrm{BF}$ with age in girls the same basic model was used for $\% \mathrm{BF}$ in girls. For $\% \mathrm{BF}$ in boys, we used a basic model including age, age $\times$ age, age $\times$ age $\times$ age, time, baseline consumption of each beverage group (MJ), its interaction with time, and the annual change in consumption (MJ). All basic models were controlled for various confounders. The following variables and their interaction with time were considered: time in years after maximal growth velocity (equals years of adolescence) as an indicator for pubertal status, weight at birth, year of birth, maternal BMI, and maternal educational level. Nine subjects were excluded due to missing values of maternal BMI, maternal educational status or weight at birth. Only those variables that significantly modified the effect of beverage consumption on BMI-SDS or \%BF in the basic models, or significantly predicted the outcome variable or improved the fit statistic (Akaike's information criterion; AIC), were included in the subsequent multivariate analyses. The basic models were also controlled for the energy deriving from other sources (residual energy) at the first assessment (total energy intake minus energy from each of the beverage groups), its interaction with time, and the annual change in residual energy. Since sufficient information on physical activity was not available for most of the study sample, it could not been considered as a possible confounder.

One supposed pathway linking consumption of energetic beverages with weight gain is an incomplete compensation for energy consumed in liquid form, and the resulting higher total energy intake. If energy from liquids were not compensated for, there would be zero correlation between beverage consumption and residual energy intake. If there were any compensation, the correlation coefficient should be negative. We therefore tested the cross-sectional correlation between the energy consumed from energetic beverages and the residual energy intake at each point in time, i.e. from time 0 to 5 (stratified by sex). Subsequently, the mean correlation coefficient was computed for boys and girls respectively. Additionally, the association between change in beverage energy and change in residual energy over the study period was tested using repeated-measures regression analysis with residual energy as the dependent variable. In all statistical tests, a $P$ value $<0.05$ was considered as significant.

\section{Results}

\section{Anthropometric measurements}

Anthropometric characteristics of the subjects are presented in Table 1. No significant differences were observed for BMI or BMI-SDS between boys and girls. However, within both boys and girls, BMI showed a significant increase from baseline to last individual assessment. BMI-SDS increased significantly only in girls, implying that girls in our sample were increasing BMI at a rate slightly in excess of the German national standard. At baseline, five boys and ten girls were overweight,

Table 1. Study sample characteristics

(Mean values and standard deviations)

\begin{tabular}{|c|c|c|c|c|c|c|c|c|}
\hline & \multicolumn{4}{|c|}{ Boys ( $n$ 125) } & \multicolumn{4}{|c|}{ Girls (n 119) } \\
\hline & \multicolumn{2}{|c|}{ Baseline } & \multicolumn{2}{|c|}{ Last assessment } & \multicolumn{2}{|c|}{ Baseline } & \multicolumn{2}{|c|}{ Last assessment } \\
\hline & Mean & SD & Mean & SD & Mean & SD & Mean & SD \\
\hline Age (years) & 11.9 & 1.6 & $16 \cdot 8$ & 1.5 & $11 \cdot 8$ & 1.5 & $16 \cdot 8$ & 1.5 \\
\hline Height (cm) & $154 \cdot 9$ & $12 \cdot 4$ & $179 \cdot 5^{\star}$ & $8 \cdot 4$ & $154 \cdot 7$ & $11 \cdot 7$ & $169 \cdot 0^{\star} \dagger$ & $6 \cdot 2$ \\
\hline Weight (kg) & $44 \cdot 3$ & $11 \cdot 0$ & $69 \cdot 1^{*}$ & $11 \cdot 7$ & $44 \cdot 8$ & 11.4 & $61 \cdot 8^{*} \dagger$ & $10 \cdot 7$ \\
\hline BMI $\left(\mathrm{kg} / \mathrm{m}^{2}\right)$ & $18 \cdot 15$ & $2 \cdot 30$ & $21 \cdot 33^{*}$ & $2 \cdot 73$ & $18 \cdot 43$ & $2 \cdot 80$ & $21 \cdot 58^{\star}$ & $3 \cdot 13$ \\
\hline BMI-SDS & -0.050 & 0.846 & 0.033 & 0.943 & -0.048 & 0.993 & $0 \cdot 117^{*}$ & 1.057 \\
\hline Overweight (\%) & \multicolumn{2}{|c|}{4} & \multicolumn{2}{|c|}{$6 \cdot 4$} & \multicolumn{2}{|c|}{$8 \cdot 4$} & \multicolumn{2}{|c|}{$5 \cdot 0$} \\
\hline Obese (\%) & \multicolumn{2}{|c|}{0} & \multicolumn{2}{|c|}{0.8} & \multicolumn{2}{|c|}{1.7} & \multicolumn{2}{|c|}{5.9} \\
\hline Body fat (\%) & $17 \cdot 8$ & $6 \cdot 2$ & $16 \cdot 4^{*}$ & $7 \cdot 8$ & $20.6 \dagger$ & $7 \cdot 1$ & $26 \cdot 3^{\star} \dagger$ & $7 \cdot 3$ \\
\hline TEI (kJ) & 8871.6 & $1887 \cdot 7$ & $11135 \cdot 0^{*}$ & $2129 \cdot 8$ & $7635 \cdot 7 \dagger$ & $1560 \cdot 7$ & $8139 \cdot 9^{\star} \dagger$ & $1605 \cdot 6$ \\
\hline
\end{tabular}

SDS, standard deviation scores; TEI, total energy intake.

${ }^{*}$ Mean value is significantly different from that at baseline $(P<0.05$; Wilcoxon signed-rank test).

† Mean value is significantly different from that of the boys $(P<0.001$; Wilcoxon rank-sum test). 
and two girls were obese. At the last assessment, eight boys and six girls were overweight, and one boy and seven girls were obese.

\section{Beverage consumption}

Characteristics of beverage consumption including non-users of a specific beverage group are shown in Table 2. In 5-year averages, regular soft drinks represented about one-quarter of the total daily beverage consumption ( $\mathrm{g}$ ) (total beverage consumption amounts to $1560 \mathrm{~g} / \mathrm{d}$ in boys and $1192 \mathrm{~g} / \mathrm{d}$ in girls and includes coffee, tea and water), namely $23.8 \%$ in boys and $20.6 \%$ in girls, while fruit juices accounted for about $14.9 \%$ in boys and $16.4 \%$ in girls. Diet soft drinks were consumed less frequently and only in small amounts.

At baseline the consumption of various beverage groups did not differ significantly between boys and girls, but consumption at the last individual assessment and long-term consumption of regular soft drinks and all energetic beverages was higher in boys (Table 2). However, percentage energy from these beverage groups, as well as the consumption of fruit juice, did not differ by sex. In contrast, the development of beverage consumption patterns differed between boys and girls. While boys increased their consumption of both beverage types within the observational time period of 5 years, girls increased their consumption of fruit juices only.

\section{Repeated-measures regression analysis}

Results of the repeated-measures regression analysis with either BMI-SDS or \%BF as dependent variables and consumption of either all energetic beverages (sum of regular soft drinks and fruit juices), or soft drinks and fruit juices as separate independent variables are shown in Tables 3-6. In boys, for all energetic beverages, in the fully adjusted model (Table 3 ; model 2) there was no association between baseline consumption and baseline BMI-SDS or \%BF. Furthermore, baseline consumption of energetic beverages did not significantly predict the change in BMI-SDS or \% BF (interaction of baseline consumption and time) in the study period. In addition, change in consumption of energetic beverages in the study period was not significantly correlated with the concurrent change in BMI-SDS or \%BF. In the models, where regular soft drinks and fruit juices were considered as separate variables (Table 4; model 2), a higher baseline consumption of fruit juices was only associated with a higher baseline BMISDS. Neither baseline consumption nor the concurrent change in consumption of fruit juices or regular soft drinks significantly predicted the change in BMI-SDS or \% BF in the study period.

In girls, the fully adjusted models (Table 5; model 2) showed that baseline consumption of energetic beverages did not predict baseline BMI-SDS, baseline \% $\mathrm{BF}$, or the change in BMI-SDS or $\% \mathrm{BF}$ in the study period. However, change in energetic beverage consumption significantly predicted the concurrent change in BMI-SDS. For each additional MJ of energetic beverages consumed in the study period, BMI-SDS of girls increased by 0.07 units in the study period $(P=0 \cdot 01)$. There was no association between change in consumption of energetic beverages and change in \%BF. Separate consideration of regular soft drinks and fruit juices (Table 6; model 2) revealed that a change in fruit juice consumption was associated with a change in BMI-SDS $(+0.096$ SDS/MJ increase in fruit juice consumption; $P=0 \cdot 01$ ). Additionally, there was a positive tendency between change in consumption of regular soft drinks and concurrent change in BMI-SDS $(+0 \cdot 055$ $\mathrm{SDS} / \mathrm{MJ}$ increase in regular soft drink consumption; $P=0 \cdot 08$ ). No association was observed between change in $\% \mathrm{BF}$ and the change in consumption of one of both beverages in the same time period. Baseline consumption of regular soft drinks or fruit juices did not predict baseline BMI-SDS, but there was an inverse correlation between baseline consumption of regular soft drinks and baseline \% $\mathrm{BF}(P=0 \cdot 05)$. Baseline consumption of both beverages did not predict the change in BMI-SDS or $\% \mathrm{BF}$ in the study period in girls. In terms of a potential compensation for liquid energy, there was in total no significant relationship between consumption of energetic beverages and residual energy intake in both sexes. The mean of six cross-sectional correlation coefficients was +0.06 for boys and -0.11 for girls, showing that consumption of energetic beverages was not adequately compensated for by restriction of other energetic foods. These findings were confirmed in the repeated-measures analysis, since baseline energy from beverages was not associated with baseline residual energy (boys $P=0.4$; girls $P=1.0$ ) or with the change in residual energy over the study period (boys $P=0 \cdot 6$; girls $P=0 \cdot 2$ ). Residual energy intake decreased significantly over the study period, when energy from beverages increased (boys $\beta=-0.28 \mathrm{MJ} /$ MJ change in beverage energy, $P=0.007$; girls $\beta=-0.27$ $\mathrm{MJ} / \mathrm{MJ}$ change in beverage energy, $P=0.016)$. However, the small observed decrease in residual energy intake could not fully compensate the increase in beverage energy.

\section{Discussion}

The main findings of the present evaluation of beverage consumption patterns and body-weight status in a sample of German adolescents are the high long-term consumption of energetic beverages (regular soft drinks plus fruit juices) and the positive association between change in energetic beverage consumption over a 5-year study period and concurrent change in BMI-SDS in girls resulting from fruit juices and to a lesser extent from regular soft drinks. In boys, there was only a positive cross-sectional association between fruit juice consumption at baseline and baseline BMI-SDS.

The boys in our sample consumed more regular soft drinks than the girls. US studies have shown similar sex differences $^{(21)}$. However, consumption of regular carbonated soft drinks was substantially higher by $350 \mathrm{~g} / \mathrm{d}$ in boys and $200 \mathrm{~g} / \mathrm{d}$ in girls in the US samples than in the DONALD sample in this analysis. On the other hand, the consumption of fruit juices in the US adolescents was much lower than in the present study (by $100-130 \mathrm{~g} / \mathrm{d}$ ). Therefore, the consumption of energetic beverages as a whole in our sample was only $230 \mathrm{~g} / \mathrm{d}$ lower in boys and $120 \mathrm{~g} / \mathrm{d}$ lower in girls in comparison with US adolescents.

In the present study, the consumption of regular soft drinks was not significantly associated with body-weight status apart from a borderline cross-sectional significance between baseline consumption of regular soft drinks and baseline \%BF in girls. Many other studies, predominantly from the USA, have examined the association between soft drink consumption 
Table 2. Characteristics of beverage group consumption in boys and girls from the Dortmund Nutritional and Anthropometric Longitudinally Designed (DONALD) study (results include users and nonusers of particular beverage groups)

(Mean values and standard deviations)

\begin{tabular}{|c|c|c|c|c|c|c|c|c|c|c|c|c|}
\hline & \multicolumn{6}{|c|}{ Boys ( $n$ 125) } & & & \multicolumn{4}{|c|}{ Girls ( $n 119)$} \\
\hline & \multicolumn{2}{|c|}{ Baseline } & \multicolumn{2}{|c|}{ Last assessment } & \multicolumn{2}{|c|}{ Long-term $\ddagger$} & \multicolumn{2}{|c|}{ Baseline } & \multicolumn{2}{|c|}{ Last assessment } & \multicolumn{2}{|c|}{ Long-term $\ddagger$} \\
\hline & Mean & SD & Mean & SD & Mean & SD & Mean & SD & Mean & SD & Mean & SD \\
\hline \multicolumn{13}{|c|}{$\begin{array}{l}\text { Energetic beverages§ } \\
\text { Consumption }(\mathrm{g} / \mathrm{d})\end{array}$} \\
\hline Mean & 455 & 326 & $732^{*}$ & 566 & 603 & 351 & 423 & 311 & $487^{*}+\dagger$ & 386 & $441+\dagger$ & 253 \\
\hline P50 & \multirow{2}{*}{\multicolumn{2}{|c|}{$\begin{array}{c}396 \\
229,643\end{array}$}} & \multirow{2}{*}{\multicolumn{2}{|c|}{$\begin{array}{c}629 \\
308,1041\end{array}$}} & \multirow{2}{*}{\multicolumn{2}{|c|}{$\begin{array}{c}521 \\
357,788\end{array}$}} & \multirow{2}{*}{\multicolumn{2}{|c|}{$\begin{array}{c}370 \\
173,594\end{array}$}} & \multirow{2}{*}{\multicolumn{2}{|c|}{$\begin{array}{c}447 \\
194,670\end{array}$}} & \multirow{2}{*}{\multicolumn{2}{|c|}{$\begin{array}{c}420 \\
236,579\end{array}$}} \\
\hline P25, P75 & & & & & & & & & & & & \\
\hline En\% & $8 \cdot 8$ & 5.9 & $10 \cdot 4^{*}$ & 7.5 & $9 \cdot 8$ & 4.9 & $9 \cdot 3$ & 6.5 & $9 \cdot 8$ & $7 \cdot 4$ & 9.3 & $5 \cdot 2$ \\
\hline $\begin{array}{l}\text { Records (\%)\| } \\
\text { Reqular soft drin }\end{array}$ & \multicolumn{2}{|c|}{$96 \cdot 0$} & \multicolumn{2}{|c|}{$96 \cdot 0$} & \multicolumn{2}{|c|}{$96 \cdot 8$} & \multicolumn{2}{|c|}{$96 \cdot 3$} & \multicolumn{2}{|c|}{96.6} & \multicolumn{2}{|c|}{$95 \cdot 0$} \\
\hline \multicolumn{13}{|c|}{$\begin{array}{l}\text { Regular soft drinks" } \\
\text { Consumbtion }(\mathrm{a} / \mathrm{d})\end{array}$} \\
\hline Mean & 277 & 296 & $455^{*}$ & 498 & 371 & 315 & 243 & 273 & $240+\dagger$ & 290 & $245+\dagger$ & 220 \\
\hline P50 & \multirow{2}{*}{\multicolumn{2}{|c|}{$\begin{array}{c}200 \\
38,403\end{array}$}} & \multirow{2}{*}{\multicolumn{2}{|c|}{$\begin{array}{c}300 \\
62,712\end{array}$}} & \multirow{2}{*}{\multicolumn{2}{|c|}{$\begin{array}{c}281 \\
130,527\end{array}$}} & \multirow{2}{*}{\multicolumn{2}{|c|}{$\begin{array}{c}167 \\
0.371\end{array}$}} & \multirow{2}{*}{\multicolumn{2}{|c|}{$\begin{array}{c}133 \\
0.400\end{array}$}} & \multirow{2}{*}{\multicolumn{2}{|c|}{$\begin{array}{c}204 \\
72.340\end{array}$}} \\
\hline P25, P75 & & & & & & & & & & & & \\
\hline En\% & $5 \cdot 1$ & $5 \cdot 1$ & 6.5 & $7 \cdot 0$ & $5 \cdot 8$ & 4.6 & $5 \cdot 2$ & $5 \cdot 6$ & 4.8 & 5.8 & $5 \cdot 1$ & 4.7 \\
\hline Records (\%)\| & & & & & & & & & & & & \\
\hline Fruit juicesł‡ & & & & & & & & & & & & \\
\hline Consumption (g/ & & & & & & & & & & & & \\
\hline Mean & 178 & 224 & $277^{*}$ & 348 & 232 & 206 & 180 & 236 & $247^{*}$ & 270 & 196 & 162 \\
\hline P50 & & & & & & & & & & & & \\
\hline P25, P75 & & & & & & & & & & & & \\
\hline En\% & 3.7 & 4.7 & 3.9 & 4.6 & 4.0 & 3.6 & $4 \cdot 1$ & $4 \cdot 8$ & $5 \cdot 0$ & $5 \cdot 2$ & 4.2 & 3.4 \\
\hline Records (\%)\| & & & & & & & & & & & & \\
\hline Diet soft drinks $\S$ & & & & & & & & & & & & \\
\hline Consumption ( $\mathrm{g} /$ & & & & & & & & & & & & \\
\hline Mean & 25 & 116 & 32 & 183 & 29 & 125 & 15 & 84 & $41^{*} \dagger$ & 135 & $27 \dagger$ & 63 \\
\hline P50 & & & & & & & & & & & & \\
\hline P25, P75 & & & & & & & & & & & & \\
\hline En\% & & & & & & & & & & & & \\
\hline Records (\%)\| & & & & & & & & & & & & \\
\hline
\end{tabular}

P, percentile; En\%, percentage of total energy intake.

Dilcoxon signed-rank test for $\mathrm{g} / \mathrm{d}$ and $\mathrm{En} \%)$.

作

Individual mean of the amounts from all weighed dietary records per subject in 5 years of study participation.

Sum of both regular soft drinks and fruit juices.

Percentage of records with consumption of the respective beverage group.

Carbonated and uncarbonated sweetened drinks.

$\S \S$ Low-energy soft drinks. 
Table 3. Results of the mixed linear model of the association between consumption of energetic beverages (EB) and body-weight status of boys (n 119) in the Dortmund Nutritional and Anthropometric Longitudinally Designed (DONALD) study*

\begin{tabular}{|c|c|c|c|c|c|c|c|}
\hline & \multicolumn{2}{|c|}{ Baseline MJ from EB } & \multicolumn{2}{|c|}{$\begin{array}{l}\text { Baseline MJ from } \\
\qquad \mathrm{EB} \times \text { time }\end{array}$} & \multicolumn{2}{|c|}{ Change in MJ from EB } & \multirow[b]{2}{*}{ AIC } \\
\hline & $\beta$ & $P$ & $\beta$ & $P$ & $\beta$ & $P$ & \\
\hline \multicolumn{8}{|l|}{ BMI-SDS } \\
\hline Model $1 \dagger$ & 0.306 & 0.034 & 0.029 & 0.212 & 0.002 & 0.905 & $669 \cdot 1$ \\
\hline Model $2 \ddagger$ & 0.204 & 0.159 & 0.034 & 0.157 & 0.005 & 0.798 & 724.7 \\
\hline \multicolumn{8}{|l|}{ Body fat (\%) } \\
\hline Model $1 \S$ & 1.086 & 0.358 & -0.051 & 0.840 & -0.008 & 0.975 & $3720 \cdot 0$ \\
\hline Model 2\| & 0.926 & 0.463 & -0.063 & 0.817 & -0.013 & 0.958 & $3765 \cdot 7$ \\
\hline
\end{tabular}

AIC, Akaike's information criterion; BMI-SDS, BMI standard deviation score.

${ }^{*}$ EB: sum of regular soft drinks and fruit juices.

$\dagger$ Adjusted for time and age.

$\ddagger$ Adjusted for time, age, residual energy at baseline, change in residual energy, weight at birth, weight at birth $\times$ time, years of adolescence, years of adolescence $\times$ time, maternal BMI, and maternal BMI $\times$ time.

$\S$ Adjusted for time, age, age $\times$ age, and age $\times$ age $\times$ age

$\|$ Adjusted for time, age, age $\times$ age, age $\times$ age $\times$ age, residual energy at baseline, residual energy at baseline $\times$ time, change in residual energy, weight at birth $\times$ time, year of birth, year of birth $\times$ time, years of adolescence, years of adolescence $\times$ time, maternal BMI, maternal BMI $\times$ time, and maternal education level $\times$ time.

Table 4. Results of the mixed linear model of the association between consumption of regular soft drinks (RSD) and fruit juices (FJ) and body-weight status of boys ( $n 119)$ in the Dortmund Nutritional and Anthropometric Longitudinally Designed (DONALD) study* ${ }^{*}$

\begin{tabular}{|c|c|c|c|c|c|c|c|c|c|c|c|c|c|}
\hline & \multicolumn{2}{|c|}{$\begin{array}{l}\text { Baseline MJ } \\
\text { from RSD }\end{array}$} & \multicolumn{2}{|c|}{$\begin{array}{c}\text { Baseline } \\
\text { MJ from } \\
\text { RSD } \times \text { time }\end{array}$} & \multicolumn{2}{|c|}{$\begin{array}{l}\text { Change in MJ } \\
\text { from RSD }\end{array}$} & \multicolumn{2}{|c|}{$\begin{array}{l}\text { Baseline MJ } \\
\text { from FJ }\end{array}$} & \multicolumn{2}{|c|}{$\begin{array}{l}\text { Baseline MJ } \\
\text { from FJ × time }\end{array}$} & \multicolumn{2}{|c|}{$\begin{array}{l}\text { Change in MJ } \\
\text { from FJ }\end{array}$} & \multirow[b]{2}{*}{ AIC } \\
\hline & $\beta$ & $\mathrm{P}$ & $\beta$ & $P$ & $\beta$ & $P$ & $\beta$ & $P$ & $\beta$ & $P$ & $\beta$ & $P$ & \\
\hline \multicolumn{14}{|l|}{ BMI-SDS } \\
\hline Model $1 \ddagger$ & 0.203 & 0.237 & 0.027 & 0.325 & 0.007 & 0.764 & 0.453 & 0.022 & 0.032 & 0.318 & -0.006 & 0.850 & $678 \cdot 1$ \\
\hline Model $2 \S$ & 0.046 & 0.793 & 0.037 & 0.211 & 0.009 & 0.707 & 0.407 & 0.039 & 0.033 & 0.310 & -0.002 & 0.964 & 743.0 \\
\hline \multicolumn{14}{|l|}{ Body fat (\%) } \\
\hline Model $1 \|$ & 0.226 & 0.872 & -0.048 & 0.872 & 0.057 & 0.839 & 2.302 & 0.156 & -0.048 & 0.891 & -0.124 & 0.749 & $3715 \cdot 1$ \\
\hline Model 2ף & -0.238 & 0.878 & -0.033 & 0.920 & 0.046 & 0.870 & $2 \cdot 112$ & 0.219 & -0.058 & 0.874 & -0.121 & 0.756 & $3756 \cdot 1$ \\
\hline
\end{tabular}

AIC, Akaike's information criterion; BMI-SDS, BMI standard deviation score.

${ }^{\star}$ RSD: carbonated and uncarbonated sugar-sweetened drinks such as lemonades, iced tea and fruit drinks (diluted and sugar-sweetened fruit juices), sports drinks and energy drinks.

†FJ: $100 \%$ fruit juice.

$\ddagger$ Adjusted for time and age.

$\S$ Adjusted for time, age, residual energy at baseline, change in residual energy, weight at birth, weight at birth $\times$ time, years of adolescence, years of adolescence $\times$ time, maternal education level, maternal education level $\times$ time, maternal $\mathrm{BMI}$, and maternal $\mathrm{BMI} \times$ time.

$\|$ Adjusted for time, age, age $\times$ age, and age $\times$ age $\times$ age.

ๆ Adjusted for time, age, age $\times$ age, age $\times$ age $\times$ age, residual energy at baseline, residual energy $\times$ time, weight at birth, weight at birth $\times$ time, years of adolescence, years of adolescence $\times$ time, year at birth, year at birth $\times$ time, maternal education level, maternal education level $\times$ time, maternal BMI, and maternal BMI $\times$ time.

Table 5. Results of the mixed linear model of the association between consumption of energetic beverages (EB) and body-weight status of girls $(n 116)$ in the Dortmund Nutritional and Anthropometric Longitudinally Designed (DONALD) study*

\begin{tabular}{|c|c|c|c|c|c|c|c|}
\hline & \multicolumn{2}{|c|}{ Baseline $\mathrm{MJ}$ from EB } & \multicolumn{2}{|c|}{$\begin{array}{l}\text { Baseline } \mathrm{MJ} \text { from } \\
\qquad \mathrm{EB} \times \text { time }\end{array}$} & \multicolumn{2}{|c|}{$\begin{array}{l}\text { Change in MJ } \\
\text { from EB }\end{array}$} & \multirow[b]{2}{*}{$\mathrm{AIC}$} \\
\hline & $\beta$ & $P$ & $\beta$ & $P$ & $\beta$ & $P$ & \\
\hline \multicolumn{8}{|l|}{ BMI-SDS } \\
\hline Model $1 \dagger$ & -0.127 & 0.495 & -0.021 & 0.397 & 0.065 & 0.015 & $666 \cdot 9$ \\
\hline Model 2ł & -0.119 & 0.473 & -0.018 & 0.463 & 0.070 & 0.010 & $703 \cdot 8$ \\
\hline \multicolumn{8}{|l|}{ Body fat (\%) } \\
\hline Model $1 \dagger$ & $-2 \cdot 198$ & 0.091 & -0.147 & 0.562 & 0.507 & 0.081 & 3487.7 \\
\hline Model 2§ & $-2 \cdot 148$ & 0.075 & -0.118 & 0.636 & 0.538 & 0.064 & $3470 \cdot 2$ \\
\hline
\end{tabular}

AIC, Akaike's information criterion; BMI-SDS, BMI standard deviation score.

${ }^{*}$ EB: sum of regular soft drinks and fruit juices.

† Adjusted for time and age.

$\ddagger$ Adjusted for time, age, residual energy at baseline, change in residual energy, weight at birth, weight at birth $\times$ time, years of adolescence, years of adolescence $\times$ time, maternal BMI, and maternal BMI $\times$ time.

$\S$ Adjusted for time, age, residual energy at baseline, weight at birth, years of adolescence, and maternal BMI. 
Table 6. Results of the mixed linear model of the association between consumption of regular soft drinks (RSD) and fruit juices (FJ) and body-weight status of girls $(n 116)$ in the Dortmund Nutritional and Anthropometric Longitudinally Designed (DONALD) study* ${ }^{*}$

\begin{tabular}{|c|c|c|c|c|c|c|c|c|c|c|c|c|c|}
\hline & \multicolumn{2}{|c|}{$\begin{array}{c}\text { Baseline MJ from } \\
\text { RSD }\end{array}$} & \multicolumn{2}{|c|}{$\begin{array}{l}\text { Baseline MJ from } \\
\text { RSD } \times \text { time }\end{array}$} & \multicolumn{2}{|c|}{$\begin{array}{l}\text { Change in MJ } \\
\text { from SD }\end{array}$} & \multicolumn{2}{|c|}{$\begin{array}{l}\text { Baseline MJ from } \\
\text { FJ }\end{array}$} & \multicolumn{2}{|c|}{$\begin{array}{l}\text { Baseline MJ from } \\
\text { FJ × time }\end{array}$} & \multicolumn{2}{|c|}{$\begin{array}{l}\text { Change in MJ } \\
\text { from FJ }\end{array}$} & \multirow[b]{2}{*}{ AIC } \\
\hline & $\beta$ & $P$ & $\beta$ & $P$ & $\beta$ & $P$ & $\beta$ & $P$ & $\beta$ & $P$ & $\beta$ & $P$ & \\
\hline \multicolumn{14}{|l|}{ BMI-SDS } \\
\hline Model 1‡ & -0.292 & 0.206 & 0.004 & 0.904 & 0.051 & 0.101 & 0.070 & 0.777 & -0.051 & 0.123 & 0.088 & 0.020 & $672 \cdot 9$ \\
\hline Model $2 \S$ & -0.291 & 0.168 & 0.005 & 0.877 & 0.055 & 0.081 & 0.069 & 0.755 & -0.046 & 0.161 & 0.096 & 0.013 & $719 \cdot 2$ \\
\hline \multicolumn{14}{|l|}{ Body fat (\%) } \\
\hline Model 1f & $-3 \cdot 186$ & 0.0477 & -0.065 & 0.834 & 0.441 & 0.192 & -1.015 & 0.553 & -0.244 & 0.465 & 0.619 & 0.135 & $3483 \cdot 2$ \\
\hline Model 2\| & -2.937 & 0.050 & 0.006 & 0.987 & 0.450 & 0.186 & -1.182 & 0.457 & -0.265 & 0.426 & 0.615 & 0.139 & $3476 \cdot 6$ \\
\hline
\end{tabular}

AIC, Akaike's information criterion; BMI-SDS, BMI standard deviation score.

${ }^{\star}$ RSD: carbonated and uncarbonated sugar-sweetened drinks such as lemonades, iced tea and fruit drinks (diluted and sugar-sweetened fruit juices), sports drinks and energy drinks.

†FJ: $100 \%$ fruit juice.

$\ddagger$ Adjusted for time and age.

$\S$ Adjusted for time, age, residual energy at baseline, change in residual energy, weight at birth, weight at birth $\times$ time, years of adolescence, years of adolescence $\times$ time, maternal education level, maternal education level $\times$ time, maternal BMI, and maternal BMI $\times$ time.

$\|$ Adjusted for time, age, residual energy at baseline, change in residual energy, weight at birth, years of adolescence, years of adolescence $\times$ time, maternal education level $\times$ time, maternal BMI, and maternal BMI $\times$ time.

and body-weight status in children and adolescents. Overall, these studies have suggested a positive association between soft drink consumption and body weight. Conflicting results may be explained in part by differences in the definitions of beverage groups (specifically inconsistent definitions of regular soft drinks), the different study designs and the varying age of the study samples.

Results from the eleven cross-sectional studies, which represent the majority of studies on this topic, are inconsistent. Five found a positive association ${ }^{(22-26)}$, whereas six failed to find a significant relationship soft drink consumption and body-weight status ${ }^{(27-32)}$. However, three of these latter six observed a positive association between regular soft drink consumption and total energy intake, a possible pathway by which energetic beverages could lead to increasing body weight $^{(30-32)}$.

The results from seven prospective studies in children and adolescents are more consistent; five found a positive association between intake of regular soft drinks and body-weight status $^{(10,33-36)}$. Of the two studies that failed to find any significant relationship, one suffered from a relatively short follow-up period of only 4-8 weeks and a small study sample $(n 21)^{(11)}$, while the other examined 2-5-year-old chil$\operatorname{dren}^{(37)}$, an age group with usually low consumption of regular soft drinks and more accurate compensation for high liquid energy intake than older children ${ }^{(38)}$. Finally, two intervention studies observed a positive development of body-weight status after restriction of regular soft drinks in the intervention group in comparison with the control group ${ }^{(39,40)}$.

Our findings are in line with the suggested positive association between regular soft drink consumption and body-weight status found in the prospective studies described above, when regular soft drinks and fruit juices were combined into a single beverage group (i.e. energetic beverages). Specifically, the present results suggest that an increase in total energetic beverage consumption predicted a concurrent increase in BMISDS in girls. This result is similar to that in the study by Gillis \& Bar-Or ${ }^{(22)}$, who did not find a significant association for soda alone, but for a combination of soda and other sugaradded drinks. The above-mentioned differences in beverage consumption between adolescents of the DONALD study and US adolescents might be one reason why regular soft drink consumption as a separate variable was not significantly associated with change in BMI-SDS, but the combined variable, energetic beverages, did predict the change in BMI-SDS.

In the present study, the prospective association of energetic beverage consumption and body-weight status was confined to girls only. This finding is in line with results of Tordoff \& Alleva ${ }^{(41)}$, who noticed an even higher weight gain in young adult females in comparison with males at a comparable level of regular soft drink consumption. Novotny et al. ${ }^{(25)}$ observed that a $1 \mathrm{~g}$ increase in soda consumption was associated with a rise of $0.005 \mathrm{~kg}$ in body weight in 323 girls between 9 and 14 years. Consumption of these beverages in both studies was far higher than the amounts in girls in our sample. However, overweight girls in particular are prone to under-reporting of undesirable, high-energy food groups ${ }^{(17)}$. Even though we excluded obviously implausible records from the analysis, this food-specific under-reporting may result in an underestimation of the relationship between energetic beverage consumption and body-weight status in girls and could be an explanation for the inverse relationship of baseline soft drink consumption and baseline \%BF. In boys, puberty results in much higher changes in energy demands as compared with girls. Thus, pubertal development may have obscured a potential effect of soft drink and energetic beverage consumption on body-weight status in boys. In fact, the only significant result found in boys was a cross-sectional relationship between fruit juice consumption at baseline and baseline BMI-SDS. However, the lack of a stratified analysis for boys and girls in some of the other studies might be another reason for inconsistent results between studies.

In both sexes, we did not observe a relationship between energetic beverage consumption and $\% \mathrm{BF}$. To date, the association with \%BF has only been evaluated in three cross-sectional studies and one prospective study ${ }^{(9,22,25,34)}$, but only Gillis \& Bar-Or ${ }^{(22)}$ observed a significant positive association between sugar-sweetened beverage consumption and $\% \mathrm{BF}$ measured by bioelectrical impedance analysis. 
Physiological differences between subjects due to pubertal changes might be one reason for inconsistent results from different studies. Another explanation may be missing information on physical activity. A high level of physical activity is associated with increased water loss. This water loss should be compensated for by a higher beverage consumption. Therefore, high levels of physical activity and the resulting energy expenditure may result in high intakes of energetic beverages. Furthermore, the specific influence of physical activity on lean body mass could mask effects of high energetic beverage consumption on \%BF. Differences in levels of physical activity between boys and girls may explain why consumption of energetic beverages affected change in BMI-SDS of girls only. Overall, despite a missing association with \%BF, the observed increase in BMI-SDS associated with increased beverage consumption in adolescence indicates a higher risk of becoming overweight and developing the pathology of the metabolic syndrome in adulthood ${ }^{(42)}$.

Results from our evaluation suggest an increase of 0.07 units in BMI-SDS for every additional unit in energetic beverage consumption over the 5-year study period (MJ) in girls. Ludwig et al. ${ }^{(10)}$ noticed that the BMI of adolescents increased by 0.18 units within 19 months for each daily serving of sugar-sweetened drinks consumed at baseline. Even though a clinical study design might be more suitable for estimating a dose-effect relationship between beverage consumption and body-weight status, these results give an impression of the quantitative effect of energetic beverage consumption, which although not remarkable at first sight, is substantial for a single food group.

One discussed pathway, by which energetic beverage consumption could lead to overweight, is an increase in total energy intake, which was observed in several studies in children and adolescents ${ }^{(9,30-32,43)}$. In fact, we found no correlation between consumption of energetic beverages and residual energy intake in both boys and girls. Apparently, energy consumed as part of energetic beverages is not fully compensated for by lower consumption of other energy-containing foods and may result in a higher total energy intake. Another mechanism that has been discussed for the impact of sweetened drinks on body weight is the use of high-fructose maize syrup, the most common sweetener in US soft drinks. Since fructose is metabolised independently from insulin, and therefore causes an unregulated absorption of fructose by hepatocytes and adipocytes, it has been proposed as a relatively uncontrolled source of carbon precursors to lipogenesis ${ }^{(13,44)}$. Interestingly, in the present study the adverse effect of an increased consumption of energetic beverages on the development of BMI-SDS of girls was to a larger extent due to an increased consumption of fruit juices, which are (despite their higher social acceptance) also characterised by a high fructose content. Currently, the exact mechanism of the effect of energetic beverages on body-weight status remains unclear.

Besides the missing information on physical activity, further limitations, and also the strengths, of the present study warrant mentioning. Dietary data were self-reported and therefore might be subject to recording errors and under-reporting. However, most other studies on beverage consumption and overweight measured dietary intake using FFQ and/or (repeated) $24 \mathrm{~h}$ recalls, both of which are prone to misjudge portion size in children and adolescents, in contrast to weighed dietary records. The high standard of the dietary records in the DONALD study has been recently shown in an analysis comparing dietary iodine intake from weighed amounts of different food groups with concurrent $24 \mathrm{~h}$ urinary iodine excretion, which reflected precisely the iodine content of food groups measured by chemical analysis $^{(45)}$. Furthermore, our long-term study design with annually repeated dietary and anthropometric measurements is more suitable for the evaluation of the effect of long-term diet on the development of body-weight status than a crosssectional design.

The elaborate design of the DONALD study results in a relatively small study sample, which is not representative with respect to socio-economic status. Nevertheless, no or only minor differences were observed when the dietary habits of the DONALD study population were compared with the results for this age group from the first nationwide German dietary survey $1987-8^{(46,47)}$. In addition, time trends in intakes observed in this population are similar to nationwide results ${ }^{(48)}$. Therefore, our selected sample appears to reflect common patterns of beverage consumption in German adolescents.

\section{Conclusion}

Our data from a sample of German adolescents showed that an increase in energetic beverage consumption was associated with an increase in BMI-SDS of girls. In boys, there was only a cross-sectional relationship between baseline consumption of fruit juices and baseline BMI-SDS. Even though we observed no effect on $\% \mathrm{BF}$, the consumption of energetic beverages may increase the risk of becoming overweight, at least in adolescent girls.

\section{Acknowledgements}

The present study was supported by the German Federal Ministry of Food, Agriculture and Consumer Protection. L. L. conducted the statistical analyses and wrote the manuscript. M. K., L. L., and U. A. conceived the research project. W. S.-H., N. K.-D. and A. E. B. provided technical support and statistical expertise. P. S. and M. K. supervised the study. All authors contributed to interpretation of the data and revision of the manuscript. None of the authors had any conflict of interest.

We are very grateful to the staff of the Research Institute of Child Nutrition for carrying out the anthropometric measurements and for collecting and coding the dietary records, and to Ellen Koeppen for proofreading the manuscript. Special thanks go to David Jacobs, $\mathrm{PhD}$, for his constructive comments related to the development of the statistical models and the interpretation of the results.

\section{References}

1. Livingstone B (2000) Epidemiology of childhood obesity in Europe. Eur J Pediatr 159, Suppl. 1, S14-S34.

2. Ogden CL, Carroll MD, Curtin LR, McDowell MA, Tabak CJ \& Flegal KM (2006) Prevalence of overweight and obesity in the United States, 1999-2004. JAMA 295, 1549-1555.

3. Kurth B-M \& Schaffrath Rosario A (2007) The prevalence of overweight and obese children and adolescents living 
in Germany. Results of the German Health Interview and Examination Survey for Children and Adolescents (KiGGS) (article in German). Bundesgesundheitsblatt Gesundheitsforschung Gesundheitsschutz 50, 736-743.

4. Edmunds L, Waters E \& Elliott EJ (2001) Evidence based paediatrics: evidence based management of childhood obesity. BMJ 323, 916-919.

5. Popkin BM \& Nielsen SJ (2003) The sweetening of the world's diet. Obes Res 11, 1325-1332.

6. Guthrie JF \& Morton JF (2000) Food sources of added sweeteners in the diets of Americans. $J$ Am Diet Assoc 100, 43-51.

7. Krebs-Smith SM (2001) Choose beverages and foods to moderate your intake of sugars: measurement requires quantification. $J$ Nutr 131, 527S-535S.

8. Malik VS, Schulze MB \& Hu FB (2006) Intake of sugar-sweetened beverages and weight gain: a systematic review. Am J Clin Nutr 84, 274-288.

9. Harnack L, Stang J \& Story M (1999) Soft drink consumption among US children and adolescents: nutritional consequences. $J$ Am Diet Assoc 99, 436-441.

10. Ludwig DS, Peterson KE \& Gortmaker SL (2001) Relation between consumption of sugar-sweetened drinks and childhood obesity: a prospective, observational analysis. Lancet 357, 505-508.

11. Mrdjenovic G \& Levitsky DA (2003) Nutritional and energetic consequences of sweetened drink consumption in 6- to 13-yearold children. J Pediatr 142, 604-610.

12. Dennison BA (1996) Fruit juice consumption by infants and children: a review. J Am Coll Nutr 15, Suppl. 5, 4S-11S.

13. Jürgens H, Haass W, Castañeda TR, et al. (2005) Consuming fructose-sweetened beverages increases body adiposity in mice. Obes Res 13, 1146-1156.

14. Kroke A, Manz F, Kersting M, Remer T, Sichert-Hellert W, Alexy U \& Lentze MJ (2004) The DONALD study. History, current status and future perspectives. Eur J Nutr 43, 45-54.

15. Sichert-Hellert W, Kersting M \& Manz F (2001) Fifteen year trends in water intake in German children and adolescents: results of the DONALD study. Dortmund Nutritional and Anthropometric Longitudinally Designed Study. Acta Paediatr 90, 732-737.

16. Schofield WN (1985) Predicting basal metabolic rate, new standards and review of previous work. Hum Nutr Clin Nutr 39, Suppl. 1, 5-41.

17. Sichert-Hellert W, Kersting M \& Schoch G (1998) Underreporting of energy intake in 1 to 18 year old German children and adolescents. Z Ernahrungswiss 37, 242-251.

18. Sichert-Hellert W, Kersting M, Chahda C, Schaefer R \& Kroke A (2007) German food composition database for dietary evaluations in children and adolescents. J Food Compos Anal 20, $63-70$.

19. Kromeyer-Hauschild K, Wabitsch M, Kunze D, et al. (2001) Percentiles of body mass index in children and adolescents evaluated from different regional German studies (article in German). Monatsschrift Kinderheilkd 149, 807-818.

20. Slaughter MH, Lohman TG, Boileau RA, Horswill CA, Stillman RJ, Van Loan MD \& Bemben DA (1988) Skinfold equations for estimation of body fatness in children and youth. Hum Biol $\mathbf{6 0}$, 709-723.

21. Food Surveys Research Group (1999) Food and nutrient intakes by children 1994-96, 1998. Washington, DC: US Department of Agriculture, Agricultural Research Service. http://www.barc. usda.gov/bhnrc/foodsurvey/home.htm (accessed 10 January 2006).

22. Gillis LJ \& Bar-Or O (2003) Food away from home, sugarsweetened drink consumption and juvenile obesity. J Am Coll Nutr 22, 539-545.

23. Giammattei J, Blix G, Marshak HH, Wollitzer AO \& Pettitt DJ (2003) Television watching and soft drink consumption: associations with obesity in 11- to 13-year-old schoolchildren. Arch Pediatr Adolesc Med 157, 882-886.

24. Nicklas TA, Yang SJ, Baranowski T, Zakeri I \& Berenson G (2003) Eating patterns and obesity in children. The Bogalusa Heart Study. Am J Prev Med 25, 9-16.

25. Novotny R, Daida YG, Acharya S, Grove JS \& Vogt TM (2004) Dairy intake is associated with lower body fat and soda intake with greater weight in adolescent girls. J Nutr 134, 1905-1909.

26. Troiano RP, Briefel RR, Carroll MD \& Bialostosky K (2000) Energy and fat intakes of children and adolescents in the United States: data from the national health and nutrition examination surveys. Am J Clin Nutr 72, 1343S-1353S.

27. Forshee RA, Anderson PA \& Storey ML (2004) The role of beverage consumption, physical activity, sedentary behavior, and demographics on body mass index of adolescents. Int J Food Sci Nutr 55, 463-478.

28. Forshee RA \& Storey ML (2003) Total beverage consumption and beverage choices among children and adolescents. Int $J$ Food Sci Nutr 54, 297-307.

29. Janssen I, Katzmarzyk PT, Boyce WF, Vereecken C, Mulvihill C, Roberts C, Currie C \& Pickett W (2005) Comparison of overweight and obesity prevalence in school-aged youth from 34 countries and their relationships with physical activity and dietary patterns. Obes Rev 6, 123-132.

30. O'Connor T, Yang S \& Nicklas T (2006) Beverage intake among preschool children and its effect on weight status. $J$ Pediatrics 118, e1010-e1017.

31. Rajeshwari R, Yang SJ, Nicklas TA \& Berenson GS (2005) Secular trends in children's sweetened-beverage consumption (1973 to 1994): the Bogalusa Heart Study. J Am Diet Assoc 105, 208-214.

32. Rodriguez-Artalejo F, Garcia EL, Gorgojo L, Garces C, Royo MA, Martin Moreno JM, Benavente M, Macias A \& De Oya M (2003) Consumption of bakery products, sweetened soft drinks and yogurt among children aged 6-7 years: association with nutrient intake and overall diet quality. Br J Nutr 89, 419-429.

33. Berkey CS, Rockett HR, Field AE, Gillman MW \& Colditz GA (2004) Sugar-added beverages and adolescent weight change. Obes Res 12, 778-788.

34. Phillips SM, Bandini LG, Naumova EN, Cyr H, Colclough S, Dietz WH \& Must A (2004) Energy-dense snack food intake in adolescence: longitudinal relationship to weight and fatness. Obes Res 12, 461-472.

35. Striegel-Moore RH, Thompson D, Affenito SG, et al. (2006) Correlates of beverage intake in adolescent girls: the National Heart, Lung, and Blood Institute Growth and Health Study. J Pediatr 148, 183-187.

36. Welsh JA, Cogswell ME, Rogers S, Rockett H, Mei Z \& Grummer-Strawn LM (2005) Overweight among low-income preschool children associated with the consumption of sweet drinks: Missouri, 1999-2002. Pediatrics 115, e223-e229.

37. Newby PK, Peterson KE, Berkey CS, Leppert J, Willett WC \& Colditz GA (2004) Beverage consumption is not associated with changes in weight and body mass index among low-income preschool children in North Dakota. J Am Diet Assoc 104, 1086-1094.

38. Cecil JE, Palmer CN, Wrieden W, Murrie I, Bolton-Smith C, Watt P, Wallis DJ \& Hetherington MM (2005) Energy intakes of children after preloads: adjustment, not compensation. $\mathrm{Am}$ $J$ Clin Nutr 82, 302-308.

39. Ebbeling CB, Feldman HA, Osganian SK, Chomitz VR, Ellenbogen SJ \& Ludwig DS (2006) Effects of decreasing sugar-sweetened beverage consumption on body weight in adolescents: a randomized, controlled pilot study. Pediatrics 117, $673-680$. 
40. James J, Thomas P, Cavan D \& Kerr D (2004) Preventing childhood obesity by reducing consumption of carbonated drinks: cluster randomised controlled trial. BMJ 328, 1237.

41. Tordoff MG \& Alleva AM (1990) Effect of drinking soda sweetened with aspartame or high-fructose corn syrup on food intake and body weight. Am J Clin Nutr 51, 963-969.

42. Wabitsch M (2004) Obese children and adolescents in Germany. A call for action (article in German). Bundesgesundheitsblatt Gesundheitsforschung Gesundheitsschutz 47, 251-255.

43. Davy BM, Harrell K, Stewart J \& King DS (2004) Body weight status, dietary habits, and physical activity levels of middle school-aged children in rural Mississippi. South Med J 97, 571-577.

44. Bray GA (2004) The epidemic of obesity and changes in food intake: the fluoride hypothesis. Physiol Behav 82, 115-121.
45. Remer T, Fonteyn N, Alexy U \& Berkemeyer S (2006) Longitudinal examination of 24-h urinary iodine excretion in schoolchildren as a sensitive, hydration status-independent research tool for studying iodine status. Am J Clin Nutr 83, 639-646.

46. Kersting M, Sichert-Hellert W, Alexy U, Manz F \& Schoch G (1998) Macronutrient intake of 1 to 18 year old German children and adolescents. Z Ernahrungswiss 37, 252-259.

47. Alexy U, Kersting M, Sichert-Hellert W, Manz F \& Schoch G (1998) Energy intake and growth of 3- to 36-month-old German infants and children. Ann Nutr Metab 42, 68-74.

48. Alexy U, Sichert-Hellert W \& Kersting M (2002) Fifteen-year time trends in energy and macronutrient intake in German children and adolescents: results of the DONALD study. Br J Nutr 87, 595-604. 